\title{
Age-dependent decrease of Nurr1 protein expression in the gerbil hippocampus
}

\author{
JI HYEON AHN ${ }^{1 *}$, JOON SEOK LEE ${ }^{2 *}$, JUN HWI CHO $^{2}$, JOON HA PARK $^{1}$, TAE-KYEONG LEE $^{3}$, \\ MINAH SONG ${ }^{3}$, HYUNJUNG KIM $^{3}$, SEOK HOON KANG ${ }^{4}$, MOO-HO WON ${ }^{3}$ and CHOONG HYUN LEE ${ }^{5}$ \\ ${ }^{1}$ Department of Biomedical Science and Research Institute for Bioscience and Biotechnology, Hallym University, \\ Chuncheon, Gangwon 24252; ${ }^{2}$ Department of Emergency Medicine and Institute of Medical Sciences, \\ Kangwon National University Hospital, School of Medicine, Kangwon National University; ${ }^{3}$ Department of Neurobiology, \\ School of Medicine, Kangwon National University; ${ }^{4}$ Department of Medical Education, School of Medicine, \\ Kangwon National University, Chuncheon, Gangwon 24341; ${ }^{5}$ Department of Pharmacy, College of Pharmacy, \\ Dankook University, Cheonan, Chungcheongnam 31116, Republic of Korea
}

Received March 12, 2018; Accepted May 2, 2018

DOI: $10.3892 /$ br.2018.1094

\begin{abstract}
Nuclear receptor related-1 protein (Nurr1) serves important roles in hippocampal-dependent cognitive process. In the present study, the protein expression of Nurr1 was compared in the hippocampi of young [postnatal month 3 (PM 3)], adult (PM 12) and aged (PM 24) gerbils using western blot analysis and immunohistochemistry. Results indicated that the protein level of Nurr1 was significantly and gradually decreased in the gerbil hippocampus with increasing age. In addition, strong Nurr1 immunoreactivity was primarily observed in pyramidal neurons and granule cells of the hippocampus in the young group, which was determined to be reduced in the adult group and to a greater extent in the aged group. Collectively the data demonstrated that Nurr1 immunoreactivity was gradually and markedly decreased during normal aging. These results indicate that gradual decrease of Nurrl expression in the hippocampus may be associated with the normal aging process and a decline in hippocampus-dependent cognitive function.
\end{abstract}

Correspondence to: Professor Moo-Ho Won, Department of Neurobiology, School of Medicine, Kangwon National University, 1 Kangwondaehak-gil, Chuncheon, Gangwon 24341, Republic of Korea E-mail:mhwon@kangwon.ac.kr

Professor Choong Hyun Lee, DVM, Department of Pharmacy, College of Pharmacy, Dankook University, 119 Dandae-ro, Dongnam-gu, Cheonan, Chungcheongnam 31116, Republic of Korea

E-mail: anaphy@dankook.ac.kr

${ }^{*}$ Contributed equally

Key words: aging, cognitive function, gerbil, hippocampus, nuclear receptor related-1 protein

\section{Introduction}

As part of the normal aging process, neuroanatomical and neurophysiological changes occur in the central nervous system (CNS) $(1,2)$, and our group previously reported age-dependent increase in antioxidant-like protein-1 expression in the gerbil hippocampus (3). In the brain, normal aging affects the functions of N-methyl-D-aspartate receptors, which may serve important roles in the initiation of long-term potentiation and be associated with age-related decline in memory $(4,5)$. Critical for learning and memory, the hippocampus is considered to be one of the brain regions most sensitive to changes induced by the normal aging process $(6,7)$.

Nuclear receptor related-1 protein (Nurr1), also known as nuclear receptor subfamily 4 group a member 2 , is a member of the inducible nuclear receptor superfamily of transcription factors (8). Nurr1 mRNA expression has been reported in several regions of the CNS, including parts of the cortex, hippocampal formation and substantia nigra, in developing and adult mice and rats (9). It has been documented that Nurr1 is associated with differentiation, maturation, function and survival of midbrain dopaminergic neurons and that reduction of Nurrl expression or polymorphisms in the Nurrl gene may be associated with Parkinson's disease etiology (10-15). Nurr1 may protect against inflammation-induced dopaminergic neuronal death by inhibiting expression of pro-inflammatory mediators in microglia and astrocytes (16). Furthermore, a recent study demonstrated that Nurrl participated in the regulation of adult hippocampal neurogenesis, and that activation of Nurrl using amodiaquine increased hippocampal neurogenesis by stimulating neural stem cells (17). In addition, Nurr1 has been observed to be under the regulation of neural activity in cultured hippocampal neurons, in that basal expression of Nurrl was reduced when neuronal activities were blocked (18).

A number of studies on Nurrl have been performed in dopaminergic neurons, and significant decrease in Nurr1 expression has been reported in dopaminergic neurons of the substantia nigra in aged humans and rats $(19,20)$. However, whether there 
is age-related change of Nurrl expression in the hippocampus, a region which has been associated with neurogenesis and neural activity (21), is yet to be fully elucidated. Therefore, the objective of the present study was to investigate age-dependent change of Nurrl protein expression in the hippocampi of young, adult and aged gerbils, as a suitable model for research on aging (22), using western blot analysis and immunohistochemistry. Overall this aimed to provide novel insight into the association of Nurrl with the decline of hippocampus-dependent cognitive function during the normal aging process.

\section{Materials and methods}

Experimental animals. The present study used male Mongolian gerbils (Meriones unguiculatus) at postnatal month 3 (PM 3; 40-50 g) as a young-group, PM 12 (65-75 g) as an adult-group and PM 24 (85-95 g) as an aged-group (total, $\mathrm{n}=42 ; \mathrm{n}=14$ /group). This model was selected due to its suitability for research on aging (22). The gerbils were obtained from the Experimental Animal Center of Kangwon National University (Chuncheon, Republic of Korea). The animals were housed under conventional conditions at an ambient temperature $\left(23 \pm 3^{\circ} \mathrm{C}\right)$ and relative humidity $(55 \pm 5 \%)$ under a 12-h light/dark cycle and were allowed free access to food and water. The study was conducted to minimize the number of gerbils. The procedures for animal handling and care adhered to guidelines in compliance with the current international laws and policies (Guide for the Care and Use of Laboratory Animals, The National Academies Press, 8th ed., 2011) (23). All experimental procedures involving animals were approved by the Institutional Animal Care and Use Committee of Kangwon National University (approval no. KW-160802-2).

Western blot analysis. Changes in Nurr1 protein levels during the normal aging process were examined in the hippocampi of gerbils ( $n=7 /$ group). Western blot analysis was performed according to the method described in our previous studies $(24,25)$. In brief, following euthanasia of the animals, hippocampi were removed. The hippocampi were homogenized and centrifuged, and the supernatants were subjected to western blot analysis. The tissues were homogenized in $50 \mathrm{mM}$ phosphate-buffered saline (PBS; pH 7.4) containing $0.1 \mathrm{mM}$ ethylene glycol-bis(2 -aminoethylether)-N,N,N',N'-tetraacetic acid ( $\mathrm{pH} 8.0), 0.2 \%$ Nonidet P-40, $10 \mathrm{mM}$ ethylendiamine tetraacetic acid $(\mathrm{pH} 8.0)$, $15 \mathrm{mM}$ sodium pyrophosphate, $100 \mathrm{mM} \beta$-glycerophosphate, 50 $\mathrm{mM} \mathrm{NaF}, 150 \mathrm{mM} \mathrm{NaCl}, 2 \mathrm{mM}$ sodium orthovanadate, $1 \mathrm{mM}$ phenylmethylsulfonyl floride and $1 \mathrm{mM}$ dithiothreitol (DTT; all from Sigma-Aldrich; Merck KGaA, Darmstadt, Germany). Following centrifugation at $16,000 \times \mathrm{g}$ for $20 \mathrm{~min}$ at $4^{\circ} \mathrm{C}$, the protein level of Nurrl in the supernatants was determined using a micro bicinchoninic acid protein assay kit (Sigma-Aldrich; Merck KGaA), with bovine serum albumin as the standard (Pierce; Thermo Fisher Scientific, Inc., Waltham, MA, USA). Aliquots containing $20 \mu \mathrm{g}$ total protein were boiled in loading buffer containing $150 \mathrm{mM}$ Tris (pH 6.8), 3 mM DTT, 6\% SDS, $0.3 \%$ bromophenol blue and $30 \%$ glycerol. The aliquots were then loaded onto a $10 \%$ polyacrylamide gel. Following electrophoresis, the gels were transferred onto nitrocellulose transfer membranes. To reduce background staining, the membranes were incubated with $5 \%$ non-fat dry milk in PBS containing
$0.1 \%$ Tween-20 for $45 \mathrm{~min}$ at room temperature. Following three washes with PBS with Tween-20 (PBST; each for 5 $\min )$, the membranes were incubated with rabbit anti-Nurr1 (PA5-13416; 1:500; Invitrogen; Thermo Fisher Scientific, Inc.) overnight at $4^{\circ} \mathrm{C}$. Following another three washes with PBST (each for $10 \mathrm{~min}$ ), the membranes were incubated with peroxidase-conjugated donkey anti-rabbit immunoglobulin $\mathrm{G}$ (IgG; sc-2305; 1:1,000; Santa Cruz Biotechnology, Inc., Dallas, TX, USA) for $1 \mathrm{~h}$ at room temperature, followed by ECL reagents (Pierce; Thermo Fisher Scientific, Inc.). The resulting protein bands were scanned, and densitometric analysis for quantification of the bands was performed using Image J 1.59 software (National Institutes of Health, Bethesda, MD, USA), which was used to calculate relative optical density (ROD). The protein level of Nurrl was normalized to that of $\beta$-actin (A5316; 1:5,000; Sigma-Aldrich; Merck KGaA). A ratio of the ROD was calibrated as a percentage, with the young-group designated as $100 \%$.

Immunohistochemistry. The gerbils ( $\mathrm{n}=7 /$ group) were anesthetized with pentobarbital sodium $(40 \mathrm{mg} / \mathrm{kg}$, intraperitoneal injection; JW Pharmaceutical Corporation, Seoul, Republic of Korea) and perfused transcardially with 0.1 M PBS (pH 7.4) followed by $4 \%$ paraformaldehyde in $0.1 \mathrm{M}$ PBS ( $\mathrm{pH} 7.4$ ). The brains were removed and postfixed with the same fixative for $7 \mathrm{~h}$ at room temperature. The brain tissue including the hippocampi was sectioned at $30-\mu \mathrm{m}$ thickness with a cryostat.

To examine age-related changes in Nurrl immunoreactivity in young, adult and aged hippocampi, immunohistochemical staining was performed according to the method described in our previous studies $(24,25)$. Immunohistochemical staining for Nurrl was performed using the rabbit anti-Nurr1 antibody $(1: 100)$ as the primary antibody overnight at $4^{\circ} \mathrm{C}$. Following three washes with PBS (each for $10 \mathrm{~min}$ ), the brain tissues were incubated with biotinylated goat anti-rabbit IgG (BA-1000; 1:200; Vector Laboratories, Burlingame, CA, USA) for $2 \mathrm{~h}$ at room temperature, and then streptavidin peroxidase complex (SA-5004; 1:200; Vector Laboratories) for $45 \mathrm{~min}$ at room temperature. To establish the specificity of the immunostaining, a negative control test without primary antibody was performed, which resulted in the absence of immunoreactivity in all structures.

A total of six sections at $120-\mu \mathrm{m}$ intervals per animal were selected to quantitatively analyze Nurr1 immunoreactivity. Digital images of Nurr1 immunoreactive structures of the hippocampal regions were observed and captured with an Axio Imager 2 light microscope (Carl Zeiss AG, Oberkochen, Germany) equipped with a digital camera (Axiocam; Carl Zeiss). According to the method of previous studies $(24,26)$, semi-quantification of the immunostaining intensity of Nurr1 was evaluated and analyzed using Image J 1.59. The mean intensity of Nurr1 immunoreactivity in the immunoreactive structures was measured using a 0-255 gray scale system (white to dark signal corresponding to 255 to 0 ). Based on this approach, the background density was subtracted, and the level of immunoreactivity was scaled as,,,- \pm+++ or +++ , representing no staining (gray scale value, $\geq 200$ ), weakly positive (gray scale value, 150-199), moderate (gray scale value, 100-149), strong (gray scale value, 50-99) or very strong (gray scale value, $\leq 49)$, respectively. 
Cresyl violet $(\mathrm{CV})$ staining. $\mathrm{CV}$ staining was performed to investigate cellular distribution and morphology. In brief, according to the method of our previous study (27), the sections of the hippocampal regions were mounted on gelatin-coated microscopy slides. Cresyl violet acetate (Sigma-Aldrich; Merck KGaA) was dissolved at $1.0 \%(\mathrm{w} / \mathrm{v})$ in distilled water, and glacial acetic acid $(0.25 \% \mathrm{v} / \mathrm{v})$ was added to this solution. The sections were stained with $\mathrm{CV}$ and dehydrated by immersing in serial ethanol baths. Finally, the stained sections were mounted with Canada balsam (Kanto Chemical, Co., Inc., Tokyo, Japan). A total of six sections at $120-\mu$ m intervals per animal were selected to identify the distribution of Nurr1 immunoreactivity in the hippocampus. Digital images of $\mathrm{CV}$ stained structures were observed and captured with the Axio Imager 2 microscope and digital camera.

Statistical analysis. Data are expressed as the mean \pm standard error of the mean. Differences in the mean ROD among the groups were statistically analyzed using one-way analysis of variance followed by post hoc Bonferroni's multiple comparison tests using GraphPad InStat (version 3.05; GraphPad Software, Inc., La Jolla, CA, USA). Statistical significance was considered at $\mathrm{P}<0.05$.

\section{Results}

Age-related changes in Nurrl protein level. Results from western blot analysis indicated an age-related change of Nurr1 protein level in the gerbil hippocampus (Fig. 1). The protein expression of Nurr1 in the adult hippocampus was significantly decreased compared with that in the young hippocampus $(\mathrm{P}<0.05)$. In addition, the expression of Nurr1 in the aged hippocampus was significantly decreased compared with that in the adult and young hippocampi $(\mathrm{P}<0.05)$. Notably, the protein level of Nurr1 in the aged hippocampus was reduced by $73.6 \%$ compared with that in the young hippocampus.

Age-related change in Nurrl immunoreactivity. Age-related changes in Nurr1 immunoreactivity (Table I and Fig. 2) were identified in the hippocampus proper (CA1-3 regions). In the young group, very strong Nurrl immunoreactivity was primarily observed in pyramidal neurons of the stratum pyramidale (SP; Fig. 2A and D). In the adult group, Nurr1 immunoreactivity in pyramidal neurons was decreased compared with that in the young group (Table I and Fig. 2B and E). Furthermore, a marked reduction of Nurrl immunoreactivity in the SP was identified in the aged group, compared with that in the adult group (Table I and Fig. 2C and F).

In the dentate gyrus (DG), Nurr1 immunoreactivity was primarily observed in granule cells of the granule cell layer (GCL; Fig. 2G, H and I). Similar to the change of Nurr1 immunoreactivity in the hippocampus proper, Nurr1 immunoreactivity in the DG gradually and markedly decreased during normal aging (Table I and Fig. 2G, H and I). Therefore, Nurr1 immunoreactivity decreased in the hippocampal regions in an age-dependent manner.

$C V$ positive cells. In the young, adult and aged groups, CV positive cells were well distributed, mainly in the SP of the hippocampal CA1-3 regions, and the granular cell layer (GCL)
Table I. Mean intensity of Nurr1 immunoreactivity in principal cells of the gerbil hippocampus during normal aging.

\begin{tabular}{lccc}
\hline & \multicolumn{3}{c}{ Postnatal month } \\
\cline { 2 - 4 } & Young & Adult & Aged \\
\hline $\begin{array}{l}\text { Pyramidal neurons of } \\
\text { hippocampus proper }\end{array}$ & +++ & ++ & + \\
$\begin{array}{l}\text { Granule cells of } \\
\text { dentate gyrus }\end{array}$ & +++ & ++ & + \\
\hline
\end{tabular}

The level of Nurr1 immunoreactivity was defined by five grades: Negative (-), weakly positive $( \pm)$, moderate $(+)$, strong $(++)$ and very strong $(+++)$. Nurr1, nuclear receptor related-1 protein.

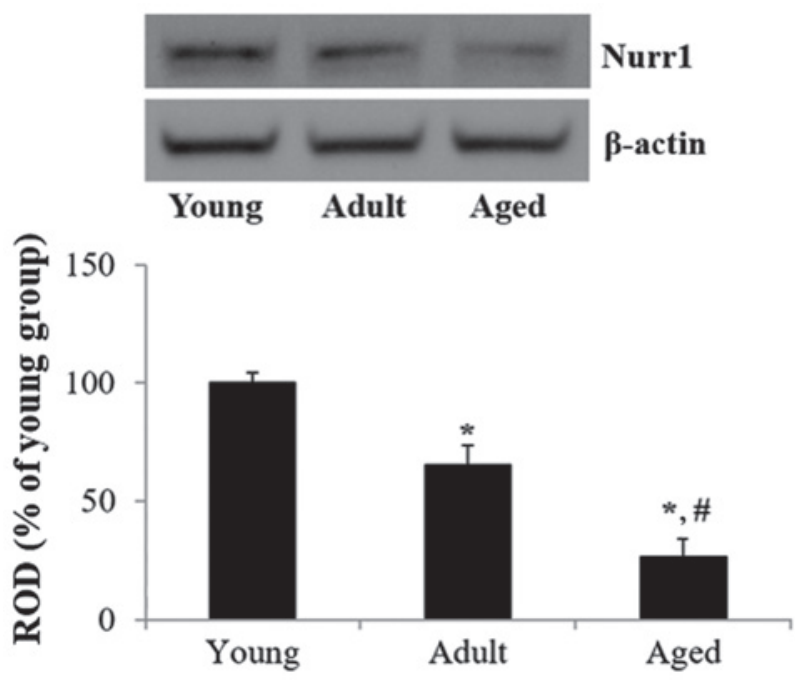

Figure 1. Western blot analysis of Nurr1 protein expression in hippocampi derived from young, adult and aged gerbils. The RODs of immunoblot bands are shown as percentage values. Data are presented as the means \pm standard error of the mean. ${ }^{*} \mathrm{P}<0.05$ vs. young group; ${ }^{\sharp} \mathrm{P}<0.05$ vs. adult group. Nurr1, nuclear receptor related-1 protein; ROD, relative optical density.

and polymorphic layer (PL) of the DG in the hippocampus (Fig. 3A-I). The distribution of Nurr1 immunoreactivity was concentrated to pyramidal neurons of the SP in the hippocampus proper and to granule cells of the GCL in the DG when comparing with the results of CV staining (Fig. 3).

\section{Discussion}

In the present study, Nurrl immunoreactivity was primarily observed in pyramidal neurons and granule cells, which are well established as principal neurons of the hippocampus (28), in young, adult and aged gerbil hippocampi. The results of Nurr1 immunoreactivity in the hippocampi were generally consistent with those of a previous study in C57BL/6 mice, which demonstrated that clear and specific Nurr1 immunoreactivity occurred in the hippocampus (29).

Chu et al (19) reported that Nurrl protein was significantly reduced in the substantia nigra of elderly human subjects. Furthermore, they identified a significant age-dependent decline in the number of Nurr1-immunoreactive neurons 


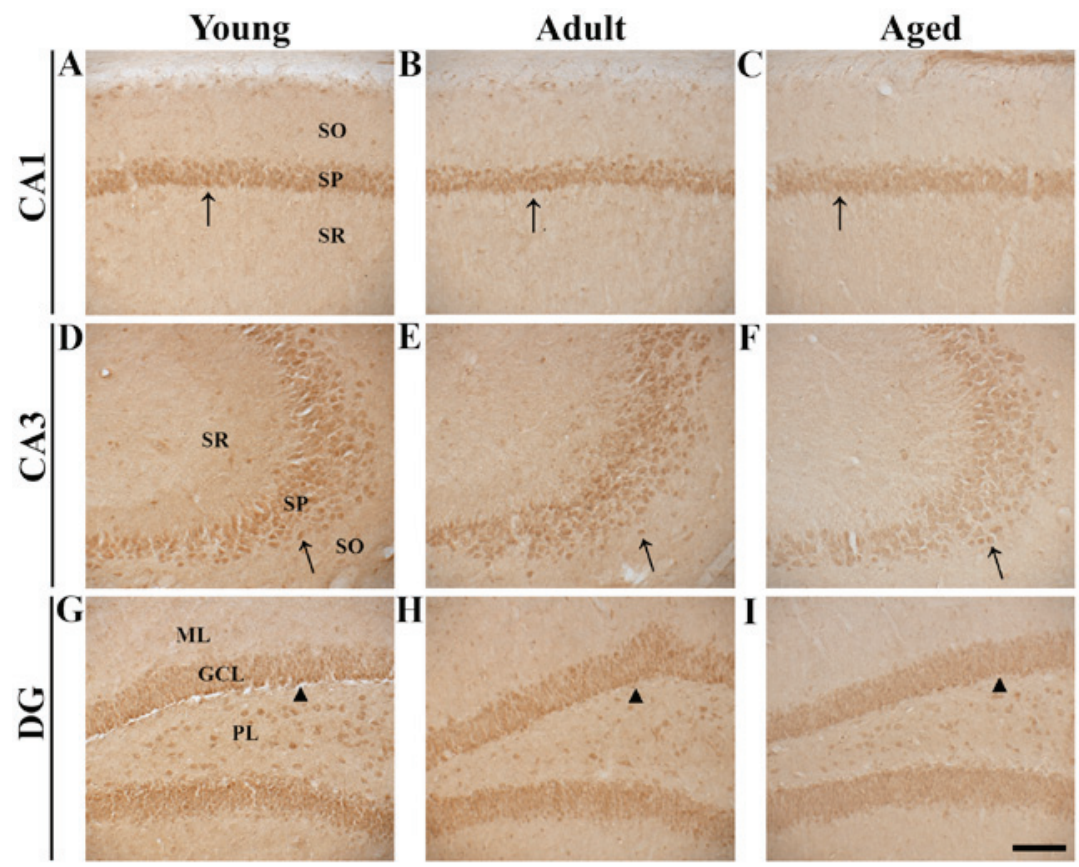

Figure 2. Nurrl immunohistochemistry in hippocampal regions of young, adult and aged gerbils. Nurrl expression was detected in the (A-C) CA1 and (D-F) CA3 regions and (G-I) DG. In the young group, strong Nurr1 immunoreactivity was detected in pyramidal neurons of the SP in the CA1 and 3 regions (arrows) and in granule cells of the GCL in the DG (arrowheads). Nurr1 immunoreactivity in the SP and GCL gradually decreased in the adult and aged groups. Magnification, x20; scale bar, $100 \mu \mathrm{m}$. Nurrl, nuclear receptor related-1 protein; DG, dentate gyrus; SO, stratum oriens; SP, stratum pyramidale; SR, stratum radiatum; ML, molecular layer; GCL, granule cell layer; PL, polymorphic layer.

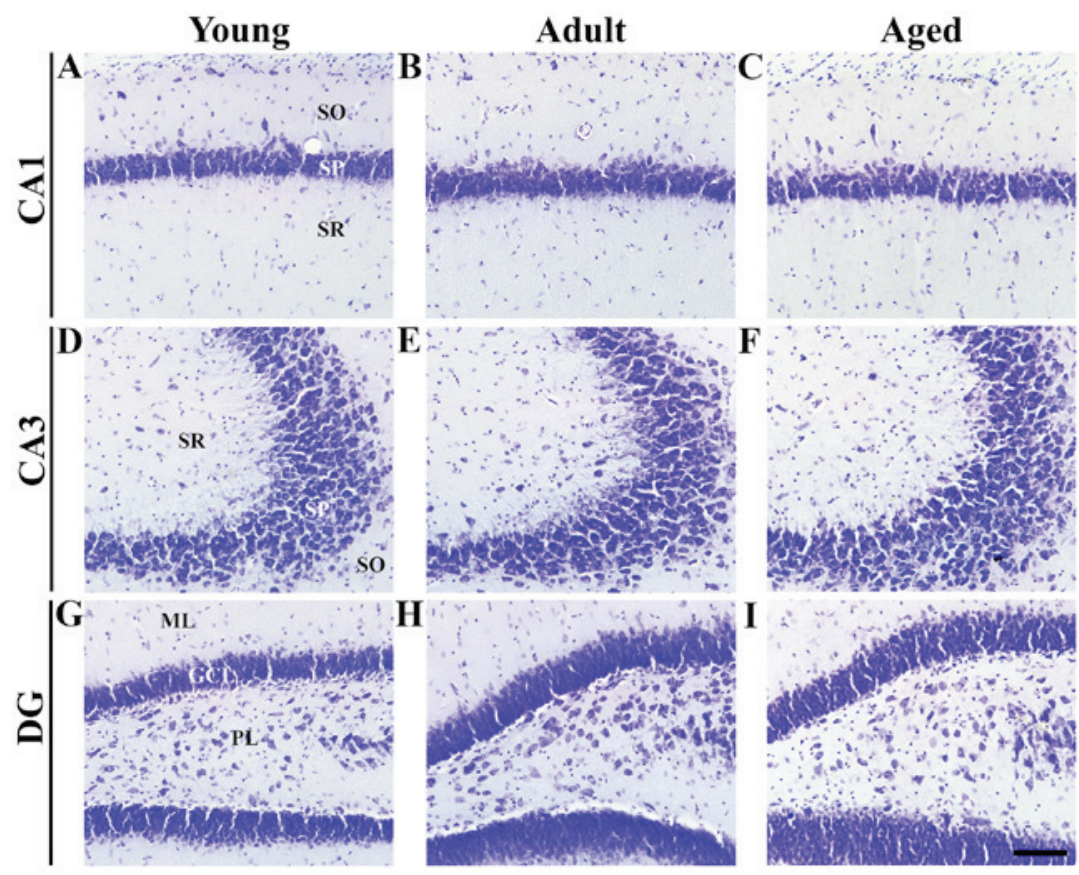

Figure 3. CV staining in hippocampal regions of young, adult and aged gerbils. Neuronal morphology and distribution was observed by CV staining in the (A-C) CA1 and (D-F) CA3 regions and (G-I) DG. In all groups, pyramidal neurons were identified in the SP in the CA1 and 3 regions, and granule cells were identified in the GCL in the DG. Magnification, x20; scale bar, $100 \mu \mathrm{m}$. CV, cresyl violet; DG, dentate gyrus; SP, stratum pyramidale; SO, stratum oriens; SR, stratum radiatum; ML, molecular layer; GCL, granule cell layer; PL, polymorphic layer.

in the substantia nigra of middle-aged and aged individuals compared with in young subjects (19). In aged rats, Nurrl gene expression has been reported to be significantly decreased by $33 \%$ in dopaminergic neurons of the substantia nigra (20); as such, it was suggested that age-dependent decrease of Nurr1 in dopaminergic neurons may be associated with impairment of nigrostriatal signaling and compromised motor function with age (20). In addition, it has been reported that heterozygous Nurrl knockout mice exhibit accelerated age-dependent reduction in the number of dopaminergic neurons and impaired dopamine signaling compared with wild-type littermate controls (30). 
In the current study, the protein level of Nurr1 in the hippocampus was significantly decreased during the normal aging process. In addition, Nurrl immunoreactivity, predominantly identified in the principal neurons (pyramidal and granule cells) of the hippocampus, was also decreased during the normal aging process. To the best of our knowledge, this is the first study to demonstrate age-dependent decrease of Nurrl protein expression in the hippocampus. However, it is difficult to conclude the implications of this marked reduction in hippocampal Nurrl due to aging. Nurrl has been considered to be among the key target genes controlled by acetylation during long-term memory formation (31), and has also been implicated to serve critical roles in the formation of long-term memory, as Nurrl expression is increased during memory acquisition and consolidation (31-34). In addition, knockdown of Nurrl or blocking Nurrl activity in the hippocampus may lead to impairment of long-lasting cognitive function (35). Principal neurons are serially or multi-directionally connected within trisynaptic hippocampal circuits for information processing (36). Pyramidal cells are involved in encoding spatial, contextual and emotional information to form cognitive memory (37), and granule cells form major structures involved in pattern separation (the ability to discriminate among similar events) (38). Therefore, it has been suggested that Nurrl, expressed in principal cells, serves critical roles in hippocampal-dependent cognitive processes (35). In addition, it has been identified that cognitive impairment begins around PM 12 and major cognitive decline occurs around PM 24 in mice (39-41). This is somewhat consistent with the present results demonstrating that Nurrl protein level and immunoreactivity in the hippocampus gradually decreased with age. Therefore, it may be postulated that a decrease of Nurrl protein expression in the hippocampus with increasing age may be associated with age-dependent cognitive impairment. However, limitations of the study include the lack of data on age-related changes in Nurrl mRNA expression, which should be obtained in future studies.

In conclusion, the present results indicate that Nurrl protein expression age-dependently decreases in the hippocampus. Overall, the findings suggest that age-dependent decrease in Nurr1 expression may be associated with a decline of cognitive function in the hippocampus.

\section{Acknowledgements}

Not applicable.

\section{Funding}

The present study was supported by the Basic Science Research Program of the National Research Foundation of Korea (NRF) funded by the Ministry of Education (grant no. NRF-2017R1D1A1B03029311) and by the Basic Science Research Program of the NRF funded by the Ministry of Science, ICT and Future Planning (grant no. NRF-2017R1A2B4009079).

\section{Availability of data and materials}

All data generated or analyzed during this study are included in this published article.

\section{Authors' contributions}

JHA, JSL, JHC, JHP, TKL, MS, HK and SHK analyzed and interpreted all data, and CHL and MHW made substantial contributions to conception and design of this study. All authors read and approved the final manuscript.

\section{Ethics approval and consent to participate}

All experimental procedures involving animals were approved by the Institutional Animal Care and Use Committee of Kangwon National University, Chuncheon, Republic of Korea (approval no. KW-160802-2).

\section{Consent for publication}

Not applicable.

\section{Competing interests}

The authors declare that they have no competing interests

\section{References}

1. Bustamante J, Czerniczyniec A, Cymeryng C and LoresArnaiz S: Age related changes from youth to adulthood in rat brain cortex: Nitric oxide synthase and mitochondrial respiratory function. Neurochem Res 33: 1216-1223, 2008.

2. He WB, Zhang JL, Hu JF, Zhang Y, Machida T and Chen NH: Effects of glucocorticoids on age-related impairments of hippocampal structure and function in mice. Cell Mol Neurobiol 28: 277-291, 2008.

3. Park JA, Park JH, Ahn JH, Kim JD, Won MH and Lee CH: Age dependent increase in the expression of antioxidant like protein 1 in the gerbil hippocampus. Mol Med Rep 14: 3215-3219, 2016.

4. Brim BL, Haskell R, Awedikian R, Ellinwood NM, Jin L, Kumar A, Foster TC and Magnusson KR: Memory in aged mice is rescued by enhanced expression of the GluN2B subunit of the NMDA receptor. Behav Brain Res 238: 211-226, 2013.

5. Márquez Loza A, Elias V, Wong CP, Ho E, Bermudez M and Magnusson KR: Effects of ibuprofen on cognition and NMDA receptor subunit expression across aging. Neuroscience 344: 276-292, 2017.

6. Geinisman Y, Detoledo-Morrell L, Morrell F and Heller RE: Hippocampal markers of age-related memory dysfunction: Behavioral, electrophysiological and morphological perspectives. Prog Neurobiol 45: 223-252, 1995.

7. Jacobson L, Zhang R, Elliffe D, Chen KF, Mathai S, McCarthy D, Waldvogel $\mathrm{H}$ and Guan J: Correlation of cellular changes and spatial memory during aging in rats. Exp Gerontol 43: 929-938, 2008.

8. Law SW, Conneely OM, DeMayo FJ and O'Malley BW: Identification of a new brain-specific transcription factor, NURR1. Mol Endocrinol 6: 2129-2135, 1992.

9. Zetterström RH, Williams R, Perlmann T and Olson L: Cellular expression of the immediate early transcription factors Nurrl and NGFI-B suggests a gene regulatory role in several brain regions including the nigrostriatal dopamine system. Brain Res Mol Brain Res 41: 111-120, 1996.

10. Jiang C, Wan X, He Y, Pan T, Jankovic J and Le W: Age-dependent dopaminergic dysfunction in Nurrl knockout mice. Exp Neurol 191: 154-162, 2005.

11. Johnson MM, Michelhaugh SK, Bouhamdan M, Schmidt CJ and Bannon MJ: The transcription factor NURR1 exerts concentration-dependent effects on target genes mediating distinct biological processes. Front Neurosci 5: 135, 2011.

12. Kadkhodaei B, Ito T, Joodmardi E, Mattsson B, Rouillard C, Carta M, Muramatsu S, Sumi-Ichinose C, Nomura T, Metzger D, et al: Nurrl is required for maintenance of maturing and adult midbrain dopamine neurons. J Neurosci 29: 15923-15932, 2009.

13. Liu H, Wei L, Tao Q, Deng H, Ming M, Xu P and Le W: Decreased NURR1 and PITX3 gene expression in Chinese patients with Parkinson's disease. Eur J Neurol 19: 870-875, 2012. 
14. Zetterström RH, Solomin L, Jansson L, Hoffer BJ, Olson L and Perlmann T: Dopamine neuron agenesis in Nurr1-deficient mice. Science 276: 248-250, 1997.

15. Zheng K, Heydari B and Simon DK: A common NURR1 polymorphism associated with Parkinson disease and diffuse Lewy body disease. Arch Neurol 60: 722-725, 2003.

16. Saijo K, Winner B, Carson CT, Collier JG, Boyer L, Rosenfeld MG, Gage FH and Glass CK: A Nurrl/CoREST pathway in microglia and astrocytes protects dopaminergic neurons from inflammationinduced death. Cell 137: 47-59, 2009.

17. Kim JI, Jeon SG, Kim KA, Kim YJ, Song EJ, Choi J, Ahn KJ, Kim CJ, Chung HY, Moon M, et al: The pharmacological stimulation of Nurr1 improves cognitive functions via enhancement of adult hippocampal neurogenesis. Stem Cell Res (Amst) 17: $534-543,2016$

18. Tokuoka H, Hatanaka T, Metzger D and Ichinose H: Nurrl expression is regulated by voltage-dependent calcium channels and calcineurin in cultured hippocampal neurons. Neurosei Lett 559: 50-55, 2014

19. Chu Y, Kompoliti K, Cochran EJ, Mufson EJ and Kordower JH: Age-related decreases in Nurrl immunoreactivity in the human substantia nigra. J Comp Neurol 450: 203-214, 2002.

20. Parkinson GM, Dayas CV and Smith DW: Age-related gene expression changes in substantia nigra dopamine neurons of the rat. Mech Ageing Dev 149: 41-49, 2015

21. Kitabatake Y, Sailor KA, Ming GL and Song H: Adult neurogenesis and hippocampal memory function: New cells, more plasticity, new memories? Neurosurg Clin N Am 18: 105-113, 2007.

22. Cheal ML: The gerbil: A unique model for research on aging. Exp Aging Res 12: 3-21, 1986

23. National Research Council: Guide for the Care and Use of Laboratory Animals. 8th edition. National Acadamies Press, Washington, DC, 2011.

24. Choi HS, Ahn JH, Park JH, Won MH and Lee CH: Age-dependent changes in the protein expression levels of Redd1 and mTOR in the gerbil hippocampus during normal aging. Mol Med Rep 13: 2409-2414, 2016.

25. Lee $\mathrm{CH}$ and Won $\mathrm{MH}$ : Increased dynamin-1 and -2 protein expression in the aged gerbil hippocampus. Cell Mol Neurobiol 34 791-796, 2014

26. Himeda T, Mizuno K, Kato H and Araki T: Effects of age on immunohistochemical changes in the mouse hippocampus. Mech Ageing Dev 126: 673-677, 2005.

27. Ahn JH, Shin BN, Park JH, Kim IH, Cho JH, Chen B, Lee TK, Tae HJ, Lee JC, Cho JH, et al: Long-term observation of neuronal degeneration and microgliosis in the gerbil dentate gyrus after transient cerebral ischemia. J Neurol Sci 363: 21-26, 2016.

28. Jinno S and Kosaka T: Stereological estimation of numerical densities of glutamatergic principal neurons in the mouse hippocampus. Hippocampus 20: 829-840, 2010.

29. Moon M, Jeong I, Kim CH, Kim J, Lee PK, Mook-Jung I, Leblanc P and Kim KS: Correlation between orphan nuclear receptor Nurrl expression and amyloid deposition in 5XFAD mice, an animal model of Alzheimer's disease. J Neurochem 132: 254-262, 2015.
30. Zhang L, Le W, Xie W and Dani JA: Age-related changes in dopamine signaling in Nurrl deficient mice as a model of Parkinson's disease. Neurobiol Aging 33: 1001.e7-16, 2012.

31. McNulty SE, Barrett RM, Vogel-Ciernia A, Malvaez M, Hernandez N, Davatolhagh MF, Matheos DP, Schiffman A and Wood MA: Differential roles for Nr4a1 and Nr4a2 in object location vs. object recognition long-term memory. Learn Mem 19: 588-592, 2012

32. McQuown SC, Barrett RM, Matheos DP, Post RJ, Rogge GA, Alenghat T, Mullican SE, Jones S, Rusche JR, Lazar MA and Wood MA: HDAC3 is a critical negative regulator of long-term memory formation. J Neurosci 31: 764-774, 2011.

33. Peña de Ortiz S, Maldonado-Vlaar CS and Carrasquillo Y: Hippocampal expression of the orphan nuclear receptor gene hzf-3/ nurrl during spatial discrimination learning. Neurobiol Learn Mem 74: 161-178, 2000.

34. von Hertzen LS and Giese KP: Memory reconsolidation engages only a subset of immediate-early genes induced during consolidation. J Neurosci 25: 1935-1942, 2005.

35. Colón-Cesario WI, Martínez-Montemayor MM,Morales S, Félix J, Cruz J, Adorno M, Pereira L, Colón N, Maldonado-Vlaar CS and Peña de Ortiz S: Knockdown of Nurrl in the rat hippocampus: Implications to spatial discrimination learning and memory. Learn Mem 13: 734-744, 2006.

36. Neves G, Cooke SF and Bliss TV: Synaptic plasticity, memory and the hippocampus: A neural network approach to causality. Nat Rev Neurosci 9: 65-75, 2008.

37. Graves AR, Moore SJ, Bloss EB, Mensh BD, Kath WL and Spruston N: Hippocampal pyramidal neurons comprise two distinct cell types that are countermodulated by metabotropic receptors. Neuron 76: 776-789, 2012.

38. Lopez-Rojas J and Kreutz MR: Mature granule cells of the dentate gyrus - Passive bystanders or principal performers in hippocampal function? Neurosci Biobehav Rev 64: 167-174, 2016.

39. Das SR and Magnusson KR: Changes in expression of splice cassettes of NMDA receptor GluN1 subunits within the frontal lobe and memory in mice during aging. Behav Brain Res 222: 122-133, 2011.

40. Yanai S, Ito H and Endo S: Long-term cilostazol administration prevents age-related decline of hippocampus-dependent memory in mice. Neuropharmacology 129: 57-68, 2018.

41. Zamzow DR, Elias V, Shumaker M, Larson C and Magnusson KR: An increase in the association of GluN2B containing NMDA receptors with membrane scaffolding proteins was related to memory declines during aging. J Neurosci 33: 12300-12305, 2013.

This work is licensed under a Creative Commons Attribution-NonCommercial-NoDerivatives 4.0 International (CC BY-NC-ND 4.0) License. 